\title{
Adaptation Study of Released Bread Wheat (Triticum aestivum L) Varieties in the Western Oromia, Ethiopia
}

\author{
Geleta Negash $^{1 *} \quad$ Wakgari Raga $^{2} \quad$ Biru Alemu $^{2}$ \\ Oromia Agricultural Research Institute (IQQO), HaroSabu Agricultural Research Center (HSARC), P.0.Box 10, \\ Kellem Wollega, Dembi Dollo
}

\begin{abstract}
Bread wheat is the most important cereal occupying a prominent position among major food crops in the world in terms of acreage and production and is an important cereal crop which is receives the most attention of specialists in plant breeding and production in the world wide. The interaction between genotypes/varieties and environment is an important for effective selection of the variety/ies. This experiment was conducted on thirteen bread wheat varieties against local check at Haro Sabu Agricultural Research Center (HSARC) sub site across environments in 2017-2018 cropping seasons to identify and recommend high yielding, insect pest tolerant, and stable varieties. The seeds were planted in Randomized Completed Block Design (RCBD) with three replications. Six agronomic traits and three economically important disease reaction data were evaluated. Analysis of variance revealed significant difference among varieties for most traits were recorded. The combine ANOVA and the additive main effects and multiplicative interactions (AMMI) analysis for grain yield across environments exhibited significantly affected by environments, explained $61.07 \%$ of the total variation.The genotype and genotype environmental interation were significant and accounted for $26.9 \%$ and $6.3 \%$ respectively. Pricipal component (PCA1) and 2 accounted for $4.3 \%$ and $1.9 \%$ of the GEI respectively with a total of $6.2 \%$ variation.Therefore, Ogolcho and Liban varieties were identified as the best varieties for yielding ability, stability, tolerant to diseases and recommended in the area and with similar agro-ecologies.
\end{abstract}

Keywords: AMMI, wheat evaluation, GGEI, Performance, stability

DOI: $10.7176 / \mathrm{JBAH} / 9-11-08$

Publication date:June $30^{\text {th }} 2019$

\section{INTRODUCTION}

Bread wheat (Triticum aestivum L.) is the most important cereal occupying a prominent position among major food crops in the world in terms of acreage and production. However, its productivity is limited by the adverse environmental conditions. In improving production, genetic variability and genotype $\mathrm{x}$ environment interaction are exploited. Genotype-environment interaction is, however, not directly measured but has to be indirect from measurements on phenotypes. This is further complicated because all genotypes do not react in a similar way to change in the environment. Different genotypes are known to show differential performances in varying environments because of the occurrence of genotype $x$ environment $(G \times E)$ interactions. This influences the relative ranking of varieties in a range of varying environmental conditions. The assessment of the nature of $\mathrm{G} x$ $E$ interactions has thus been appreciated by the plant breeders. The multi-environmental testing has been an integral part of almost all the breeding programmes. Genotype environment interactions are generally considered an impediment in plant breeding. A low level of interaction is measured for some characters so as to maximize uniformity of performance over a number of environments.

So, multi-environment yield trials are essential in estimation of genotype by environment interactionn (GEI) and identification of superior genotypes in the final selection cycles (Kaya et al., 2006; Mitrovic et al., 2012). Phenotypes are a mixture of genotype (G) and environment (E) components and interactions ( $\mathrm{G} \times \mathrm{E}$ ) between them.GxE interactions complicate process of selecting genotypes with superior performance. Consequently, Multienvironment trails (METs) are widely used by plant breeders to evaluate the relative performance of genotypes for target environments (Delacy et al., 1996).Similarly, the additive main effects and multiplicative interaction (AMMI) model have led to more understanding in the complicated patterns of genotypic responses to the environment (Gauch, 2006). These patterns have been successfully related to biotic and abiotic factors. (Yan et al., 2000), proposed another methodology known as GGE-biplot for graphical display of GE interaction pattern of MET data with many advantages. GGE biplot is an effective method based on principal component analysis (PCA) which fully explores MET data. It allows visual examination of the relationships among the test environments, genotypes and the GE interactions.

Therefore, the objective of the study was to evaluate, select and recommend high yielder, tolerant to diseases, more adapted and stable varieties.

\section{MATERIALS AND METHODS}

Area description: The multi-location yield trial (MLYT) was conducted at two different locations for two consecutive years in Kellem and west Wollega zones of Haro-sebu agricultural research center at Belem sub site 
(altitude 1759 masl, $09^{\circ} 02^{\prime} \mathrm{N}, 035^{\circ} 104^{\prime} \mathrm{E}$ ) and Badesso (altitude 2054 masl, 08 $40^{\prime} \mathrm{N}, 034^{\circ} 47^{\prime} \mathrm{E}$ ) in western Oromia, Ethiopia, during the 2017-2018 main cropping season.

Breeding materials and experimental design: Thrteen varieties including local chack (Dambal, Danda'a, Hidase, Kingbird, Lemu, Liban, Local, Mandoyu, Obora, Ogolcho, Sanate, Sofumer and Wame) were evaluated. Randomized complete block design (RCBD) with three replication and least significant difference (LSD 5\%) for mean separation were used. Six rows per plot of $0.2 \mathrm{~m}$ spacing between rows and $2.5 \mathrm{~m}$ row length and harvestable plot size was $2 \mathrm{~m}^{2}$ (four harvestable rows per plot). Seed rate of $150 \mathrm{~kg} / \mathrm{ha}$ and fertilizer rate of $100 \mathrm{~kg} / \mathrm{ha} \mathrm{DAP}$ and $150 \mathrm{~kg} / \mathrm{ha}$ Urea were used. Urea was applied in split form. All other agronomic practices were performed as per the recommendation for the crop. The trial was raised under rain fed across all the test locations. The data considered for analysis was from the candidates of the net plot, thus the four central harvestable rows. The harvested genotypes were sundried before being tested for moisture content where $12 \%$ was the preferred average moisture content using moisture tester. Grain yield data was then obtained by weighing the dried grain using a digital scale.

\section{STATISTICAL ANALYSIS}

Analysis of variance is calculated using the model:

$\mathrm{Yij}=\mu+\mathrm{Gi}+\mathrm{Ej}+\mathrm{GEij}$

Where $\mathrm{Yij}$ is the corresponding variable of the $\mathrm{i}^{\text {-th }}$ genotype in $\mathrm{j}^{\text {-th }}$ environment, $\mu$ is the total mean, Gi is the main effect of $\mathrm{i}^{\text {th }}$ genotype, $\mathrm{Ej}$ is the main effect of $\mathrm{j}^{\text {th }}$ environment, GEij is the effect of genotype $\mathrm{x}$ environment interaction.

The AMMI model used was:

$$
Y_{i j}=\mu+g_{i}+e_{j}+\sum_{1}^{N} \Lambda_{k} Y_{k k} \delta_{j k}+\varepsilon_{i}
$$

Where Yij is the grain yield of the $\mathrm{i}^{\text {-th }}$ genotype in the $\mathrm{j}^{\text {-th }}$ environment, $\mu$ is the grand mean, gi and ej are the genotype and environment deviation from the grand mean, respectively, $K \mathrm{k}$ is the eigenvalue of the principal component analysis (PCA) axis k, Yik and $\delta \mathrm{jk}$ are the genotype and environment principal component scores for axis $\mathrm{k}, \mathrm{N}$ is the number of principal components retained in the model, and Eij is the residual term.

AMMI Stability Value (ASV): ASV is the distance from the coordinate point to the origin in a twodimensional plot of IPCA1 scores against IPCA2 scores in the AMMI model (Purchase, 1997). Because the IPCA1 score contributes more to the GxE interaction sum of squares, a weighted value is needed. This weighted value was calculated for each genotype and each environment according to the relative contribution of IPCA1 to IPCA2 to the interaction sum of squares as follows:

$$
A S V=\sqrt{\left[\left(S S_{I P C A 1} \div S S_{I P C A 2}\right)(\text { IPCAlscore })\right]^{2}+(\text { IPCA2score })^{2}}
$$

Where, $\mathrm{SS}_{\text {IPCA1 }} / \mathrm{SS}_{\text {IPCA2 }}$ is the weight given to the IPCA1-value by dividing the IPCA1 sum of squares by the IPCA2 sum of squares. The larger the ASV value, either negative or positive, the more specifically adapted a genotype is to certain environments. Smaller ASV values indicate more stable genotypes across environments (Purchase, 1997). Genotype Selection Index (GSI): Stability is not the only parameter for selection as most stable genotypes would not necessarily give the best yield performance. Therefore, based on the rank of mean grain yield of genotypes (RYi) across environments and rank of AMMI stability value RASVi), genotype selection index (GSI) was calculated for each genotype as:

$$
\mathrm{GSIi}=\mathrm{RASVi}+\mathrm{RYi}
$$

A genotype with the least GSI is considered as the most stable (Farshadfar, 2008). Analysis of variance was carried out using statistical analysis system (SAS) version 9.2 software (SAS, 2008). Additive Main Effect and Multiplicative Interaction (AMMI) analysis and GGE bi-plot analysis were performed using Gen Stat 15 th edition statistical package (VSN, 2012)

Data collection method: Ten plants were selected randomly before heading from each row (four harvestable rows) and tagged with thread and all the necessary plant based data were collected from these sampled plants. Such as; days to heading, days to maturity, plant height, spike length, lodging, grain yield and three economically important disease reactions like stem rust, leaf rust and fusarium head blight.

\section{RESULTS AND DISCUSSIONS}

\section{Combined analysis of variance}

Mean square of analysis of variance for all varieties at different environmental conditions for grain yield and yield related traits are presented in Table1. Highly significant differences were detected among years $(\mathrm{P} \leq 0.01)$ for all parameters. The combined analysis of variance revealed that year and location effects were significant for all parameters except for disease reaction. Year*varieties effects were non- significant for all parameters excluding 
days to heading, days to maturity, lodging and grain yield. Year*location *varieties were significant for some traits such as days to heading, days to maturity, lodging and grain yield

Table 1: Combined Analysis of variance (ANOVA) for grain yield and yield related traits of bread wheat verities adaptation in 2017-2018 main cropping seasons.

\begin{tabular}{|c|c|c|c|c|c|c|c|c|c|c|}
\hline Source. V & DF & DH & DM & SR & LR & FHB & LDG & PH & SL & YLDkgha \\
\hline rep & 2 & 3.87 & $15.63 *$ & 0.06 & 0.03 & 0.85 & 0.05 & $142.42 *$ & $4.78^{*}$ & 1389.44 \\
\hline vrt & 12 & $147.41 * *$ & $250.67 * *$ & 0.03 & 0.02 & 0.44 & $0.10 * *$ & $544.78 * *$ & $4.69 * *$ & $3253296.11 * *$ \\
\hline loc & 1 & $156.00 * *$ & $164.10 * *$ & 0.06 & 0.03 & 0.36 & $3.85 * *$ & 86.18 & $26.79 * *$ & $2970456.28 * *$ \\
\hline yrs. & 1 & $315.92 * *$ & $1981.64 * *$ & $42.06 * *$ & $41.03 * *$ & $39.50 * *$ & $3.85 * *$ & $1353.76 * *$ & $90.39 * *$ & $13952834.08 * *$ \\
\hline vrt*loc & 12 & $7.07 * *$ & $29.21 * *$ & 0.03 & 0.02 & 0.05 & $0.10 * *$ & $111.94 * *$ & 0.53 & $227642.36^{* *}$ \\
\hline vrt*yr & 12 & $31.38 * *$ & $137.78 * *$ & 0.03 & 0.02 & 0.72 & $0.10 * *$ & 2.51 & 0.81 & $80287.90 *$ \\
\hline loc*yr & 1 & $39.00 * *$ & $481.26^{* *}$ & 0.06 & 0.03 & 0.36 & $3.85 * *$ & $202.76^{* *}$ & $29.25 * *$ & $98536.60 *$ \\
\hline vrt*loc*yr & 12 & $7.07 * *$ & $35.70 * *$ & 0.03 & 0.02 & 0.05 & $0.10 * *$ & 1.56 & 0.35 & $26050.14 *$ \\
\hline
\end{tabular}

Key ns *** non -significant, significant at $5 \%$ and $1 \%$ respectively, Loc *vrt= location by varieties, Yr*Loc*vrt $=$ year by location by varieties, DF -degree of freedom, DH- Days to Heading; DM- Days to Maturity; PH- Plant Height; SL- spike Length; YLD Kg/ha- Yield in kilogram per hectare.

\section{Agronomic performance of evaluated varieties}

Combined mean grain yield and other agronomic traits are presented in Table 2. Medium mean of days to heading, days to maturity, lodging, plant height and spike length were recorded by Kingbird and Liban varieties. However, Hidase and Mandoyu varieties were with short mean of days to heading and days to physiological maturity indicated that early maturing varieties were desirable when moisture is the limiting factors for production and productivity. Similarly, Ogolcho variety was recorded medium plant height indicated, the variety might be tolerant to lodging problem and it recorded highest spike length and grain yield.

Table 2: Combined mean grain yield and other agronomic traits performance of bread wheat varieties.

\begin{tabular}{lllllll}
\hline Varieties & DH & DM & LDG & PH & SL & KGHA \\
\hline Dambal & $70.9 \mathrm{~d}$ & $119.9 \mathrm{def}$ & $1.3 \mathrm{a}$ & $84.0 \mathrm{bc}$ & $9.0 \mathrm{abc}$ & $3221.4 \mathrm{~h}$ \\
Danda'a & $74.8 \mathrm{~b}$ & $120.9 \mathrm{~d}$ & $1.1 \mathrm{~cd}$ & $83.2 \mathrm{bcd}$ & $7.9 \mathrm{e}$ & $3786.1 \mathrm{~cd}$ \\
Hidase & $68.1 \mathrm{f}$ & $109.6 \mathrm{~h}$ & $1.2 \mathrm{abc}$ & $72.1 \mathrm{~g}$ & $8.4 \mathrm{~b}-\mathrm{e}$ & $3199.6 \mathrm{~h}$ \\
Kingbird & $\mathbf{6 8 . 7 e f}$ & $\mathbf{1 2 0 . 0 d e}$ & $\mathbf{1 . 2 b c}$ & $\mathbf{7 5 . 1 e f g}$ & $\mathbf{8 . 7 a - d}$ & $\mathbf{3 8 3 6 . 9 c}$ \\
Lemu & $70.9 \mathrm{~d}$ & $120.8 \mathrm{de}$ & $1.1 \mathrm{~cd}$ & $74.9 \mathrm{efg}$ & $9.1 \mathrm{ab}$ & $3440.9 \mathrm{~g}$ \\
Liban & $\mathbf{7 4 . 6 b}$ & $\mathbf{1 2 2 . 4 c}$ & $\mathbf{1 . 1 c d}$ & $\mathbf{7 9 . 9 c d e}$ & $\mathbf{9 . 2 a}$ & $\mathbf{4 4 7 8 . 6 b}$ \\
Local & $73.8 \mathrm{~b}$ & $124.7 \mathrm{~b}$ & $1.2 \mathrm{bc}$ & $95.0 \mathrm{a}$ & $8.1 \mathrm{de}$ & $3180.5 \mathrm{~h}$ \\
Mandoyu & $67.9 \mathrm{f}$ & $118.5 \mathrm{fg}$ & $1.2 \mathrm{bc}$ & $72.7 \mathrm{~g}$ & $8.3 \mathrm{cde}$ & $2981.4 \mathrm{i}$ \\
Obora & $79.8 \mathrm{a}$ & $130.4 \mathrm{a}$ & $1.1 \mathrm{~cd}$ & $73.9 \mathrm{fg}$ & $9.0 \mathrm{ab}$ & $3318.3 \mathrm{gh}$ \\
Ogolcho & $\mathbf{7 2 . 6 c}$ & $\mathbf{1 1 9 . 3 e f g}$ & $\mathbf{1 . 0 d}$ & $\mathbf{8 5 . 7 b}$ & $\mathbf{9 . 4 a}$ & $\mathbf{4 7 8 2 . 0 a}$ \\
Sanate & $69.6 \mathrm{e}$ & $120.2 \mathrm{ed}$ & $1.3 \mathrm{ab}$ & $82.4 \mathrm{bcd}$ & $7.7 \mathrm{e}$ & $3591.0 \mathrm{ef}$ \\
Sofumer & $68.8 \mathrm{ef}$ & $120.8 \mathrm{de}$ & $1.3 \mathrm{ab}$ & $87.2 \mathrm{~b}$ & $9.5 \mathrm{a}$ & $3691.9 \mathrm{de}$ \\
Wame & $68.6 \mathrm{ef}$ & $118.1 \mathrm{~g}$ & $1.2 \mathrm{bc}$ & $78.2 \mathrm{def}$ & $7.7 \mathrm{e}$ & $3458.1 \mathrm{fg}$ \\
\hline Mean \pm SEM & $71.46 \pm 0.35$ & $120.42 \pm 0.59$ & $1.16 \pm 0.03$ & $80.34 \pm 0.76$ & $8.61 \pm 0.12$ & $3612.81 \pm 51.16$ \\
CV\% & 1.91 & 1.47 & 13.71 & 8.01 & 10.83 & 4.91 \\
R \% & 0.94 & 0.96 & 0.86 & 0.7 & 0.72 & 0.95 \\
LSD 5\% & 1.1 & 1.43 & 0.1 & 5.2 & 0.8 & 143.7 \\
F test & $* *$ & $* *$ & $* *$ & $* *$ & $* *$ & $* *$ \\
\hline
\end{tabular}

Key: DH-Days to heading, DM-Days to maturity, PH-Plant height, SL-spike length, YLD Kg/ha- Yield in kilogram per hectare, LDG-lodging, SR-stem rust, LR-leaf rust, FHB-fusarium head blight, CV- Coefficient of variation, $\mathrm{R}^{2}$-R-squere, LSD- least significant, SEM-standard error of mean.

\section{Major disease reaction of bread wheat varieties across environments}

Most varieties evaluated had significantly low scores with their corresponding economically important disease reactions. However, some variety such as Danda'a was less tolerance to leaf rust and fusarium head blight. Similarly, Kingbird, Liban and Ogolcho varieties were better tolerance to leaf rust and fusarium head blight. On the other hand, non-significance differences were recorded for all varieties to stem rust disease reactions (Table $3)$. 
Table 3. Combined mean of disease reactions (1-5 scale) of bread wheat varieties evaluated in 2017-2018 main cropping seasons

\begin{tabular}{llll}
\hline Varieties & SR & LR & FHB \\
\hline Dambal & $0.5 \mathrm{a}$ & $0.5 \mathrm{~b}$ & $1.8 \mathrm{ab}$ \\
Danda'a & $0.5 \mathrm{a}$ & $0.6 \mathrm{a}$ & $2.3 \mathrm{a}$ \\
Hidase & $0.5 \mathrm{a}$ & $0.5 \mathrm{~b}$ & $2.0 \mathrm{ab}$ \\
Kingbird & $\mathbf{0 . 5 a}$ & $\mathbf{0 . 5 b}$ & $\mathbf{1 . 9 a b}$ \\
Lemu & $0.5 \mathrm{a}$ & $0.5 \mathrm{~b}$ & $2.0 \mathrm{ab}$ \\
Liban & $0.6 \mathrm{a}$ & $0.5 \mathrm{~b}$ & $1.9 \mathrm{ab}$ \\
Local & $0.5 \mathrm{a}$ & $0.5 \mathrm{~b}$ & $1.7 \mathrm{ab}$ \\
Mandoyu & $0.5 \mathrm{a}$ & $0.5 \mathrm{~b}$ & $2.1 \mathrm{ab}$ \\
Obora & $0.5 \mathrm{a}$ & $0.5 \mathrm{~b}$ & $1.7 \mathrm{ab}$ \\
Ogolcho & $0.6 \mathrm{a}$ & $0.6 \mathrm{ab}$ & $1.7 \mathrm{ab}$ \\
Sanate & $0.5 \mathrm{a}$ & $0.5 \mathrm{~b}$ & $1.9 \mathrm{ab}$ \\
Sofumer & $0.5 \mathrm{a}$ & $0.5 \mathrm{~b}$ & $1.6 \mathrm{ab}$ \\
Wame & $0.5 \mathrm{a}$ & $0.5 \mathrm{~b}$ & $2.0 \mathrm{ab}$ \\
\hline Mean \pm SEM & $0.52 \pm 0.04$ & $0.51 \pm 0.04$ & $1.88 \pm 0.07$ \\
CV\% & 32.39 & 24.54 & 38.72 \\
R \% & 0.94 & 0.96 & 0.51 \\
LSD 5\% & 0.14 & 0.1 & 0.6 \\
F test & $\mathrm{ns}$ & $\mathrm{ns}$ & $\mathrm{ns}$ \\
\hline
\end{tabular}

Key: CV- Coefficient of variation, LSD- least significant difference, $\mathrm{R}^{2}$-R-Squere, SR-stem rust, LR-leaf rust, FHB-fusarium head blight.1-5 scale where 1= resistant, 5= susceptible

\section{Additive main effects and multiplicative interaction (AMMI) model}

The combine ANOVA and AMMI analysis for grain yield at four environments revealed, bread wheat grain yield was significantly affected by environments, which explained $61.7 \%$ of the total variation, while the G and GEI were significant and accounted for $26.9 \%$ and $6.3 \%$ respectively (Table 4). A study by Gauch and Zobel, 1997), reported in standard multi-environment trials (METs), environment effect contributes $80 \%$ of the total sum of treatments and $10 \%$ effect of genotype and interaction. In additive variance, the portioning of GEss data matrix by using AMMI analysis indicated the first PCAs were significant $(\mathrm{P}<0.01)$. PCA 1 and 2 accounted for $4.3 \%$ and $1.9 \%$ of the GE interaction, respectively representing a total of $6.2 \%$ of the interaction variation (Table 4). Similar results have been reported in earlier studies (Mohammadi and Amri, 2009). Large yield variation explained by environments indicated, environments were diverse,with large differences between environmental means contributing maximum of the variation in grain yield (Table 5). Grain yield of environments ranged from 3201 $\mathrm{kg} / \mathrm{ha}$ in BD (Badesso-2017) to $4075 \mathrm{~kg} / \mathrm{ha}$ in MT2 (Mata-2018). The mean grain yield varied from $2981 \mathrm{~kg} / \mathrm{ha}$ for Mandoyu variety to $4782 \mathrm{~kg} / \mathrm{ha}$ for Ogolcho variety with over all mean of $3613 \mathrm{~kg} / \mathrm{ha}$ (Table 5)

Table 4: Additive main effect and multiplicative interaction analysis of variances (AMMI) for grain yield of 13 bread wheat adaptation evaluated at four locations

\begin{tabular}{lllll}
\hline Source & DF & SS & EX.SS\% & MS \\
\hline Total & 155 & 63281634 & 100 & 408269 \\
Treatments & 51 & 60068265 & 94.9 & $1177809^{* *}$ \\
Genotypes & 12 & 17021735 & 26.9 & $1418477.9^{* *}$ \\
Environments & 3 & 39038686 & 61.7 & $13012895^{* *}$ \\
Block & 8 & 17967 & 0.0 & $2246^{\mathrm{ns}}$ \\
Interactions & 36 & 4007844 & 6.3 & $111329^{* *}$ \\
IPCA 1 & 14 & 2750446 & 4.3 & $196460^{* *}$ \\
IPCA 2 & 12 & 1214973 & 1.9 & $101248^{* *}$ \\
Residuals & 10 & 42424 & 0.1 & 4242 \\
Error & 96 & 3195402 & & 33285 \\
\hline
\end{tabular}

Key: DF = degree of freedom, $\mathrm{SS}=$ sum of squares, $\mathrm{MS}=$ mean squares, IPCA = Interaction Principal Component Axis, EX. SS $\%=$ Explained Sum of square ns * ${ }^{* *}$ non-Significant ,Significant at the $0.5 \%$ and $0.1 \%$ level of probability respectively 
Table 5 Mean grain yield $\left(\mathrm{kgha}^{-1}\right)$ per location and year from the AMMI additive GE model

\begin{tabular}{llllllll}
\hline Genotype & BD & BD2 & MT & MT2 & Mean & IPCAG1 & IPCAG2 \\
\hline Dambal & 2800 & 3347 & 3044 & 3694 & $\mathbf{3 2 2 1}$ & 0.63 & 0.03 \\
Danda'a & 3575 & 4298 & 3316 & 3956 & $\mathbf{3 7 8 6}$ & -18.86 & 3.4 \\
Hidase & 2989 & 3572 & 2813 & 3424 & $\mathbf{3 2 0 0}$ & -14.19 & -0.29 \\
Kingbird & 3356 & 4038 & 3631 & 4322 & $\mathbf{3 8 3 7}$ & -0.05 & 3.95 \\
Lemu & 2895 & 3470 & 3358 & 4041 & $\mathbf{3 4 4 1}$ & 7.76 & 1.52 \\
Liban & 3900 & 4716 & 4280 & 5019 & $\mathbf{4 4 7 9}$ & 1.78 & 8.08 \\
Local & 2779 & 3320 & 2989 & 3634 & $\mathbf{3 1 8 1}$ & -0.43 & -0.24 \\
Mandoyu & 2510 & 2990 & 2889 & 3537 & $\mathbf{2 9 8 1}$ & 6.14 & -1.43 \\
Obora & 2819 & 3374 & 3205 & 3874 & $\mathbf{3 3 1 8}$ & 5.38 & 0.71 \\
Ogolcho & 4774 & 4547 & 4701 & 5104 & 4782 & -0.13 & -22.82 \\
Sanate & 3240 & 3888 & 3290 & 3946 & $\mathbf{3 5 9 1}$ & -7.3 & 2.29 \\
Sofumer & 3036 & 3650 & 3683 & 4398 & $\mathbf{3 6 9 2}$ & 13.56 & 3.2 \\
Wame & 2939 & 3523 & 3346 & 4025 & $\mathbf{3 4 5 8}$ & 5.73 & 1.61 \\
\hline Mean & $\mathbf{3 2 0 1}$ & $\mathbf{3 7 4 9}$ & $\mathbf{3 4 2 7}$ & $\mathbf{4 0 7 5}$ & $\mathbf{3 6 1 3}$ & & \\
\hline
\end{tabular}

Key: BD ( Badesso-2017), BD2 (Badesso-2018),MT (Mata -2017), MT2 (Mata-2018)

The estimation of yield and stability of varieties were done by using the average coordinates of the environment (AEC) methods (Yan, 2001; Yan and Hunt, 2001). The average environment is defined by the average values of $\mathrm{PC} 1$ and 2 for the all environments and it is presented with a circle. The average ordinate environment (AOE) defined by the line which is perpendicular to the AEA (average environment axis) line and pass through the origin. This line divides the varieties in to those with higher yield than average and in to those lower yield than average. By projecting the varieties on AEA axis, the varieties are ranked by yield, where the yield increases in the direction of arrow. In this study, the highest yield had Ogocho and Liban varieties however,the lowers had Mondayu and Hidase varieties (Figure 1). Stability of the varieties depends on their distance from the AE abscissa. Varieties closer to or around the center of concentric circle indicated these varieties are more stable than others. Therfore, the greatest stability in the high yielding varieties are Ogolcho and Liban (Figure 1). Variety ranking is shown on the graph of variety so-called "ideal" variety (Figure 1). An ideal variety is defined as one that is the highest yielding across test environments and it is completely stable in performance (that ranks the highest in all test environments) (Farshadfar et al., 2012; Yan and Kang, 2003). Even though such an "ideal" variety may not exist in reality, it could be used as a reference for variety evaluation (Mitrovic et al., 2012). A variety is more appropriate if it is located closer to "ideal" variety (Farshadfar et al., 2012; Kaya et al., 2006). So, the closer to the "ideal" varieties in this study were Ogolcho and Liban (Figure1)

Figure: 1 GGE bi-plot based on genotype-focused scaling for comparison of genotypes for their yield potential and stability

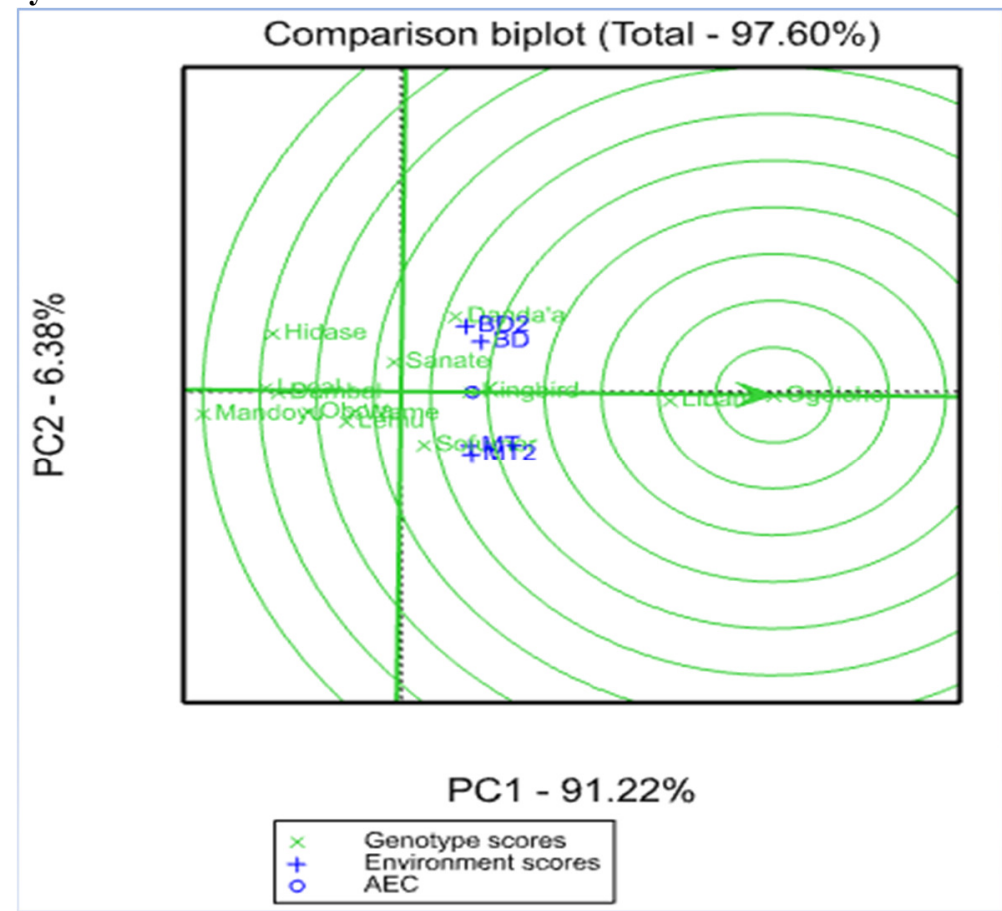


Additive main effects and multiple interactions (AMMI) stability value (ASV)

AMMI stability value (ASV): Varieties exhibited significant genotype by environment interaction effect and the additive and multiplicative interaction effect stability analysis (ASV) implied to split the interaction effect. In view of mean grain yield as a first criteria for evaluating, Ogolcho variety was the highest mean grain yield (4782 kg/ha) followed by the Liban variety with the mean grain yield of $4479 \mathrm{~kg} / \mathrm{ha}$. Whereas, Mandoyu variety was with lowest mean grain yields across the testing locations (Table 6).Varieties with lower ASV values are considered more stable and varieties with higher ASV are unstable. According to the ASV ranking in the (Table 6), Local variety was the most stable with an ASV value of 1 followed by Dambal variety with ASV value 2. However, Sofumer variety was the most unstable since higher ASV value of 13. The stable variety was followed with mean grain yield above the grand mean and this result was in agreement with (Hintsa and Abay, 2013), who has used ASV as one method of evaluating grain yield stability of bread wheat varieties in Tigray and similar reports been made by Abay and Bjørnstad (2009); Sivapalan et al. (2000) in barley in Tigray and bread wheat using AMMI stability value. A variety with the least of genotype selection index (GSI) is considered as the most stable genotype (Farshadfar, 2008). For that reason, Ogolcho was the most stable variety since with the low of genotype selection index (GSI) and the highest mean grain yield of all (Table 6).

Table 6.AMMI stability value, AMMI rank, yield, yield rank and genotype selection index (GSI)

\begin{tabular}{llllll}
\hline Varieties & ASV & ASV rank & YLD & YLD rank & GSI \\
\hline Ogolcho & 20.96 & 10 & 4782 & 1 & 11 \\
Liban & 12.45 & 9 & 4479 & 2 & 11 \\
Kingbird & 5.94 & 3 & 3837 & 3 & 6 \\
Danda'a & 28.83 & 12 & 3786 & 4 & 16 \\
Sofumer & 34.34 & 13 & 3692 & 5 & 18 \\
Sanate & 11.51 & 7 & 3591 & 6 & 13 \\
Wame & 8.96 & 5 & 3458 & 7 & 12 \\
Lemu & 11.9 & 8 & 3441 & 8 & 16 \\
Obora & 8.16 & 4 & 3318 & 9 & 13 \\
Dambal & 0.95 & 2 & 3221 & 10 & 22 \\
Hidase & 21.36 & 11 & 3200 & 11 & 13 \\
Local & 0.73 & 1 & 3181 & 12 & 19 \\
Mandoyu & 9.49 & 6 & 2981 & 13 & \\
\hline
\end{tabular}

\section{CONCLUSIONS AND RECOMMENDATIONS}

Generally, based on the two analyses of AMMI and GGE-bi-plot models, Ogolcho and Liban varieties were considered as high yielder and more stability, consequently, close to ideal variety, so these varieties are adaptable to a wide range of environmental conditions. Therefore, the two varieties were identified as ideal varieties in terms of yielding ability and stability, tolerant to diseases and better agronomic performance at multi-location evaluation.

\section{ACKNOWLEDGMENT}

The authors greatly acknowledged Oromia Agricultural Research Institute (IQQO) for financial support. HaroSebu Agricultural Research Center staff members are warmly acknowledged for technical and administrative support. Particularly, all cereal research team members significantly thankful for their technical support and field work.

\section{REFERENCES}

Abay, F. and Bjørnstad, A. (2009). Specific adaptation of barley varieties in different locations in Ethiopia. Euphotic, 167: 181-195.

Delacy, IH., Basford, KE., Cooper, M. and Bull, JK. 1996. Analysis of multi- environment trials- an historical perspective. Plant Adaptation and Crop Improvement. Eds. M. Cooper and G. L. Hammer. CAB international, pp. 39-124.

Farshadfar E (2008). Incorporation of AMMI Stability Value and Grain Yield in a Single Non-Parametric Index (Genotype Selection Index) in Bread Wheat. Pakistan Journal of Biological Sciences 11: 1791-1796.

Farshadfar, E., Mohammadi, R., Aghaee, M. and Vaisi, Z. 2012. GGE biplot analysis of genotype $\times$ environment interaction in wheat-barley disomic addition lines. Australia Journal of Crop Sciences.6:1074-1079.

Gauch, HG. 2006. Statistical analysis of yield trials by AMMI and GGE. Crop Sciences. 46:1488-1500.

Gauch, HG.and Zobel, RW. 1997. Interpreting mega-environments and targeting genotypes. Crop Sciences. 37:311-326

Hintsa, G. and Abay, F. 2013. Evaluation of Bread Wheat Genotypes for their Adaptability in wheat growing Areas of Tigray Region, northern Ethiopia. Journal of Biodiversity and Endangered Species.

Kaya, Y., Akcura, M. and Taner, S. 2006. GGE-bi-plot analysis of multi- environment yield trials in bread wheat. 
Turkish Journal of Agriculture 30:325- 337.

Mitrovic, B., Stanisavljevi, D., Treski, S., Stojakovic, M., Ivanovic, M., Bekavac, G. and Rajkovic, M. 2012. Evaluation of experimental Maize hybrids tested in Multi-location trials using AMMI and GGE bi-plot analysis. Turkish Journal of Field Crops. 17:35-40.

Mohammadi, R. and Amri, A. 2009. Analysis of Genotype $\times$ Environment Interactions for Grain Yield in Durum Wheat. Crop Sciences. 49:1177-1186.

Purchase, JL.1997. Parametric analysis to describe genotype $\mathrm{x}$ environment interaction and yield stability in winter wheat. Ph.D. Thesis, Department of Agronomy, Faculty of Agriculture of the University of the Free State, Bloemfontein, South Africa

SAS Institute Inc. 2008. Statistical analysis Software version 9.2, Cary, NC: SAS Institute Inc. USA

Sivapalan, S., Obrien, L., Ortiz-Ferrara, G., Hollamby, GJ., Barclay, I. and Martin, PJ. 2000. An adaptation analysis of Australian and CIMMYT/ICARDA wheat germplasm in Australian production environments. Crop Science pastures 51: 903-915.

VSN International, 2012. "Gen Stat for Windows 15th Edition. VSN International, Hemel Hempstead, UK." Available: www.genStat.co.uk

Yan,W.2001. GGE bi-plot- a windows application for graphical analysis of multi-environment trial data and other types of two-way data. Journal of Agronomy 93:1111-1118.

Yan, W. and Kang, MS. 2003. GGE bi-plot analysis: a graphical tool for breeders, In Kang MS, ed. Geneticists, and Agronomist. CRC Press, Boca Raton, FL, pp. 63-88.

Yan, W. and Hunt, LA., Sheng, Q. and Szlavnics, Z. 2000. Cultivar evaluation and mega environment investigation based on the GGE bi-plot. Crop Science.40:597-605.

Yan, W. and Hunt, LA.2001. Genetic and environmental causes of genotype by environment interaction for winter wheat yield in Ontario. Crop Science 41:19-25. 